has been found should be slaughtered. That is based on the assumptions either that cattle can catch the disease from those with which they are in contact or that those in the same herds have been fed the same foodstuff. That would entail the destruction of some six million animals. That draconian recipe is politically unacceptable. It is probably also unnecessary. More sensible options for action stem from the supposition that maternal transmission happens in cattle as it does in sheep. The British Veterinary Association was advocating last week that there should be a ban on breeding from the progeny of infected animals, while the British Labour Party went one step further and called for the slaughter of all offspring of BSE cattle. In each case, action is impeded by the length of the incubation period of the disease, and by the lack (in Britain) of a system for tracking the pedigree of cattle. If Gummer wishes to be seen to be acting decisively, he could do worse than take himself to Ireland, which has had a workable system of cattle identity for many years. That, of course, might be demeaning for a British mainland politician.

The economic cost of solutions involving the slaughter of 'at risk' animals is a powerful disincentive. At the current rate of compensation (up to £656 if BSE is confirmed, up to $£ 820$ if it is not), Lacey's plan would cost the government several thousand million pounds. Even the Labour party's more modest proposal could run up a bill matching the $£ 6$ million paid out to farmers so far. But there is a danger that whatever the British government spends, the economic costs to British farmers stemming from the reduced demand for beef will be greater.

What Gummer should say, as distinct from do, is another matter. Even the agriculture minister's fiercest critics seem glad that it is he, not they who is responsible. But there are a few elementary rules that a man in his position may find useful. First, "don'ts". Never say that there is no danger (risk). Instead, say that there is always a danger (risk), and that the problem is to calculate what it is. And never say that the risk is negligible unless you are sure that your listeners share your own philosophy of life.

The "dos" are philosophically more difficult, but for that reason more important. Gummer should be obliged to tell it like it is. Most probably, BSE would not have arisen if farmers had not been helped to feed processed sheep offal to cattle in the early 1980s. But they were, and the British then paid less for beef than might otherwise have been necessary. Now, with the boot on the other foot, the British will not eat beef for fear that it will kill them, and the price has fallen even further.

Gummer should be saying that predicting such an outturn would have required great feats of imagination. He should also be emphasizing the literally unknown steps in the causation of BSE. An origin in scrapie? The link with contaminated sheep feed is circumstantial only but there are ways in which BSE arising sui generis could be worse. Maternal transmission? If scrapie is a guide, maternal transmission is more likely but is similarly unproven and difficult to prove. Adventitious infection?
Almost inconceivable, given what little is known of prions, but not entirely out of court. The transfer of BSE to people as CJD? There is not even circumstantial evidence, only hypothesis.

It would not be entirely imprudent for Gummer also to juggle with a few numbers. So far, roughly one in a thousand British cattle have been affected. If the origin is scrapie, and if control measures have been properly applied, a similar number of cattle may be affected in the next five years, after which the disease should disappear. If the transfer of the BSE agent to people from cattle has been contained by the stricter regulation of offal, it is hard to think that people will have been more at risk of acquiring the agent from contaminated beef than cattle have been from contaminated feed. And that risk should now have been eliminated. So the risk that a person eating beef in Britain in the past five years would contract CJD would be between zero (if BSE cannot cause CJD) and, at the most, one in a million. That would make 50 cases of CJD spread over the next 30 years or so, compared with the present case load of about 30 cases a year. Such numbers, only illustrative, might help to take some of the anxiety out of what will otherwise be a bruising debate for all concerned.

\section{Summit's agenda}

Next week's meeting of US and Soviet presidents will be good, but could have been better.

THE Washington summit next week will go as well as can be expected. The two superpowers (if that remains the right word) will have made substantial progress towards a treaty on the use of strategic weapons. After fine-tuning on matters such as cruise missiles it will be a valuable piece of paper, when signed later in the year. It is not so much that it will help to reduce the risks of nuclear war, but that it has been made possible by the natural reduction of these risks by other causes. That is worth remembering when both sides set out to tell what difference its treaty may make to their domestic money problems.

The disappointment of next week's summit will be the two sides' failure to reach an understanding on conventional forces in Europe. This has been on the cards since Mr Mikhail Gorbachev's declaration two years ago that Soviet armed forces would be reduced by 500,000 . It has been brushed aside by the rapid pace of political change in Europe - notably by the de facto collapse of the Warsaw Pact. The Soviet Union is now dragging its feet for one plain reason - it does not wish to get rid of conventional forces while the military status of Central Europe is undeclared - and one dark reason, mounting domestic opposition to Gorbachev's policies. The summit next week could most usefully lay the basis of the long-term security of Central European states shaken loose from the Warsaw Pact. That Europe's most urgent problem is also its most difficult is no excuse for neglecting it. 